\title{
The Application of Airborne Geophysical and Satellite Imagery Data in the Delineation of Rock Boundaries and Structural Lineaments in Anka Sheet 52, Northwestern, Nigeria
}

\author{
Agunleti, Y. S* Najime. T. Ibrahim, A. A. Magaji, S. S. \\ Department of Geology, Ahmadu Bello University, Zaria. Nigeria
}

\begin{abstract}
The understanding of different lithologies and geological structures is a major task of geologists for accurate geological map during geological mapping exercise. In doing so, geologist must be able to cover broad areas of the surface or subsurface of the earth through collection of reliable remote sensing data over a wide region. The Landsat $\mathrm{ETM}^{+}$from Global Land Cover Facility (GLCV), Shuttle Radar Thematic Mapper- Digital Elevation Model (SRTM, DEM) data from Global Mapper version 14, Airborne Magnetic and Radiometric data from Nigeria Geological Survey Agency (NGSA) was acquired and interpreted with the help of computer-image processing technology such as Oasis Montaj and ArcGIS software to process, display and represent results covering the study area (Anka sheet 52). The basis of this technology is the representation of the radiometric data in a digital raster format that contain both amplitude and spatial information. In this format, the data was analyzed, enhanced for visual inspection and combined with other types of data to form colour composite images that clearly subdivide the Basement complex rocks into Pan-African Granites from the Metasediments and the most eye-catching feature is the basement-sedimentary contact. Also, a major NE-SW trending structural lineament referred to as the Anka Fault trends for almost $25 \mathrm{~km}$ and other subsidiary lineaments trending NW-SE with few E-W trends.
\end{abstract}

Keywords: Landsat $\mathrm{ETM}^{+}$, Magnetic, Radiometric, Structural Lineament, Satellite Imagery.

DOI: $10.7176 / \mathrm{JEES} / 10-1-05$

Publication date: January $31^{\text {st }} 2020$

\section{Introduction}

The major task of geologists for accurate geological features during geological mapping starts by understanding the temporal and spatial variations in the distribution and abundance of geological features on a regional scale. Therefore, to understand geological features and their relationship, geologist must be able to cover broad areas of the surface or subsurface of the earth [1] through collection of reliable data over a wide region. Luckily, the application of remote sensing techniques is providing geologists with means of acquiring these reliable regional data. Thus, the remote sensing techniques over three decades have shown a great promise for mapping geological feature variations over a wide scale ([2]; [3]; [1]). Most mineral deposits are structurally control and the recognition of geological linear structures such as fractures and lithological contacts are crucial during mineral exploration. Meanwhile, the application of various remotely sensed data such as gravity, magnetic, radiometric, visible and near infrared, imaging radar and topographic data for geological structures have been recognized to be worthwhile. The understanding of the structures within different lithologies in the Anka sheet 52 in northwestern part of Nigeria is thus considered for this research with the application of magnetic, radiometric and satellite imagery data. Figure 1 shows the position of the study area (Anka sheet 52) in the context of regional geological map of Nigeria. 


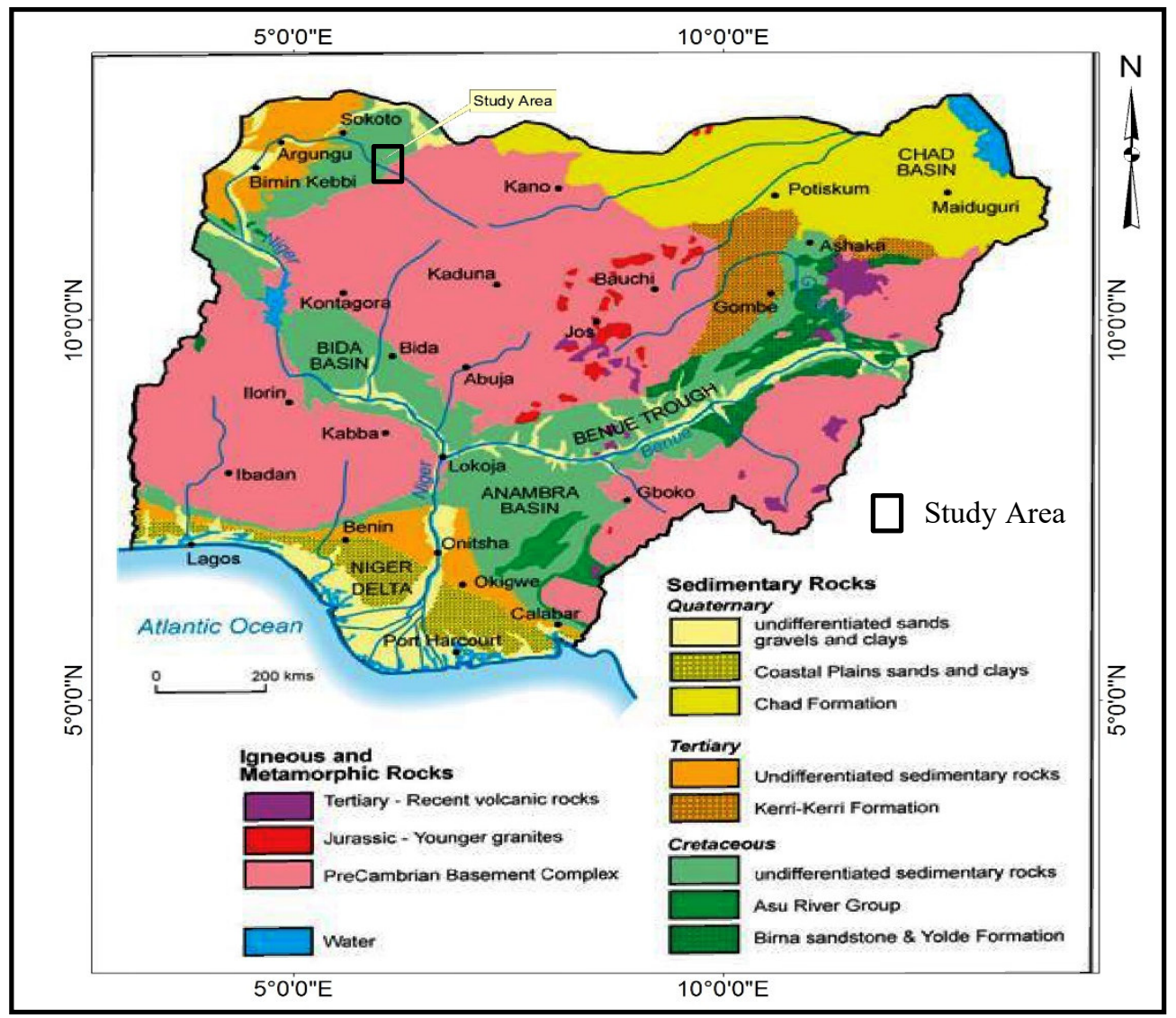

Figure 1: Geological sketch map of Nigeria showing the major geological components [4]

\section{Research Methods}

The methods employed involved the acquisition and interpretation of Landsat $\mathrm{ETM}^{+}$from Global Land Cover Facility (GLCV), Shuttle Radar Thematic Mapper- Digital Elevation Model (SRTM, DEM) data by using Global Mapper version 14, Airborne Magnetic and Radiometric data from Nigeria Geological Survey Agency (NGSA). The Shuttle Radar Topography Mission (SRTM) data sets which results from a collaborative effort by the National Aeronautics and Space Administration (NASA) and the National Geospatial-Intelligence Agency (NGA previously known as the National Imagery and Mapping Agency, or NIMA), as well as the participation of the German and Italian space agencies, to generate a near-global digital elevation model (DEM) of the Earth using radar interferometer, acquired with the aid of Global Mapper version 14 to generate terrain elevation data (XYZ), regional drainages and $10 \mathrm{~m}$ contours interval within the study area. The SRTM instrument consisted of the Space borne Imaging Radar-C (SIR-C) hardware set modified with a Space Station-derived mast and additional antennae to form an interferometer with a $60 \mathrm{~m}$ baseline. A description of the SRTM mission can be found in [5].

\subsection{Landsat image}

Landsat data (30m resolution) downloaded from Global Land Cover Facilities (GLCF) platform was orthorectified and processed to a higher quality standard. The GLCF GeoCover collection was produced under contract from NASA by Earth Sat Inc. with locational information provided by United States Geological Survey (USGS). The collection provides global, high resolution, multi-temporal imagery with corrections for distortions resulting from terrain. The data have been reviewed for geo-locational and meta-data accuracy through NASA Stennis and is free to redistribute. Users can take this imagery and use it to determine vegetation dynamics, urban sprawl, agricultural conversion, or apply it for numerous other uses. The GeoCover dataset is a standard GeoTIFF format with a UTM projection, using the WGS-84 datum. Each scene is provided with bands as separate files. Image files are compressed using gzip, so that files have a ".gz" extension and 'gunzip' the file. This opens the Landsat image band in its native GeoTIFF file format. The GeoTIFF file covering the study area was downloaded and used as a TIFF file in ArcGIS 10.4

\subsection{Airborne magnetic and radiometric data analysis}

An airborne magnetic and radiometric data was obtained from Nigerian Geological Survey Agency (NGSA). The flight parameters of the airborne magnetic and radiometric data are: Flight line spacing $(500 \mathrm{~m})$, Tie line 
spacing $(2 \mathrm{~km})$, Terrain clearance $(80 \mathrm{~m})$, Flight direction is NW-SE while the Tie line direction is NE-SW. The original total magnetic intensity (TMI) was gridded, processed, filtered and transformed to other grids such as First Vertical Derivative (1VD), Analytical signal (ANSIG), Horizontal gradient, SPI depth etc. Oasis Montaj by Geosoft and ArcGIS 10.1 by ESRI software was used to process the airborne magnetic data, relate and overlay various layers of information. The first Vertical Derivative aids the identification of near surface features such as dykes and veins to clearly identify vertical features and therefore maps out lineaments effectively, while the ANSIG combines the derivatives of independent structures of inclination/declination within induced field in order to directly generate discrete bodies and their edges. These extensions were used to analyze regional structural patterns made from deductions and interpretations of the airborne magnetic data sets. The airborne radiometric technique was efficient in the distribution of rocks within the study area regionally through the identification of Thorium (Th), Uranium (U) and Potassium (K) as processed into ternary plot [6].

\section{Results}

The results obtained from the interpretations of Landsat $\mathrm{ETM}^{+}$, Shuttle Radar Thematic Mapper (SRTM) data for Digital Elevation Model (DEM), Airborne Magnetic and Radiometric are presented below. The available free high resolution satellite image covering the study area was downloaded and processed to aid geological mapping. It is worth to mention, that accurate rectification of the image was done before processing. The aim of rectification is to minimize the geometric distortions introduced by such factors as earth curvature, relief displacement and the acquisition geometry of the satellites acquired. The regional overview of the study area in the context of a 30 meters' resolution LandSat Imagery with band combinations of 321 is shown in Figure 2. While the XYZ terrain data which represent latitude, longitude and elevation values respectively was uploaded into Surfer 10 software to plot the zoned digital elevation model of the area (Figure 3).

\subsection{Structural lineaments from aeromagnetic data}

The Total Magnetic Intensity (TMI) grid (Figure 4) was processed, filtered and transformed to first (1VD) and second vertical derivatives (2VD) images using Oasis Montaj for identification of structural trends (Figure 5 and 6). The derivatives tend to sharpen the edges of anomalies and enhance shallow features. The vertical derivative map is much more responsive to local influences than to broad or regional effects and therefore tends to give sharper picture than the map of the total field intensity. Thus the smaller anomalies are more readily apparent in area of strong regional disturbances. Enhancement of the images using Reduced to Pole (RTP) was applied to obtain a clear image of the structures and the regional structural lineaments were extracted and presented in (Figure 7).

\subsection{Geologic boundary from radiometric data}

The advances of computer-image processing technology such as Oasis was used to process, display and represent radiometric data covering the study area. The basis of this technology is the representation of the radiometry data in a digital raster format that contain both amplitude (colour) and spatial information. In this format, the data was analyzed, enhanced for visual inspection and combined with other types of data to form colour composite images. The radioelement composite image combines the data of $\mathrm{K}$ (in red), eTh (in green), and eU (in blue) as developed by the USGS. This image offers much in term of lithological discrimination based on colour differences. For this study, the interpreted individual units of potassium, uranium and thorium composite colour images (Figure 8, 9 and 10) were subjected to further refinement using the radioelement composite image (Figure 11) which offers better composite map to outline the major lithological units from different radioactivity levels and its corroborates with clear boundary/lithologic interpretation by enhanced radioelement (Figure 12). The integrated results aided geological boundary and structural lineament map of the study area (Anka sheet 52) as shown in Figure 13. 


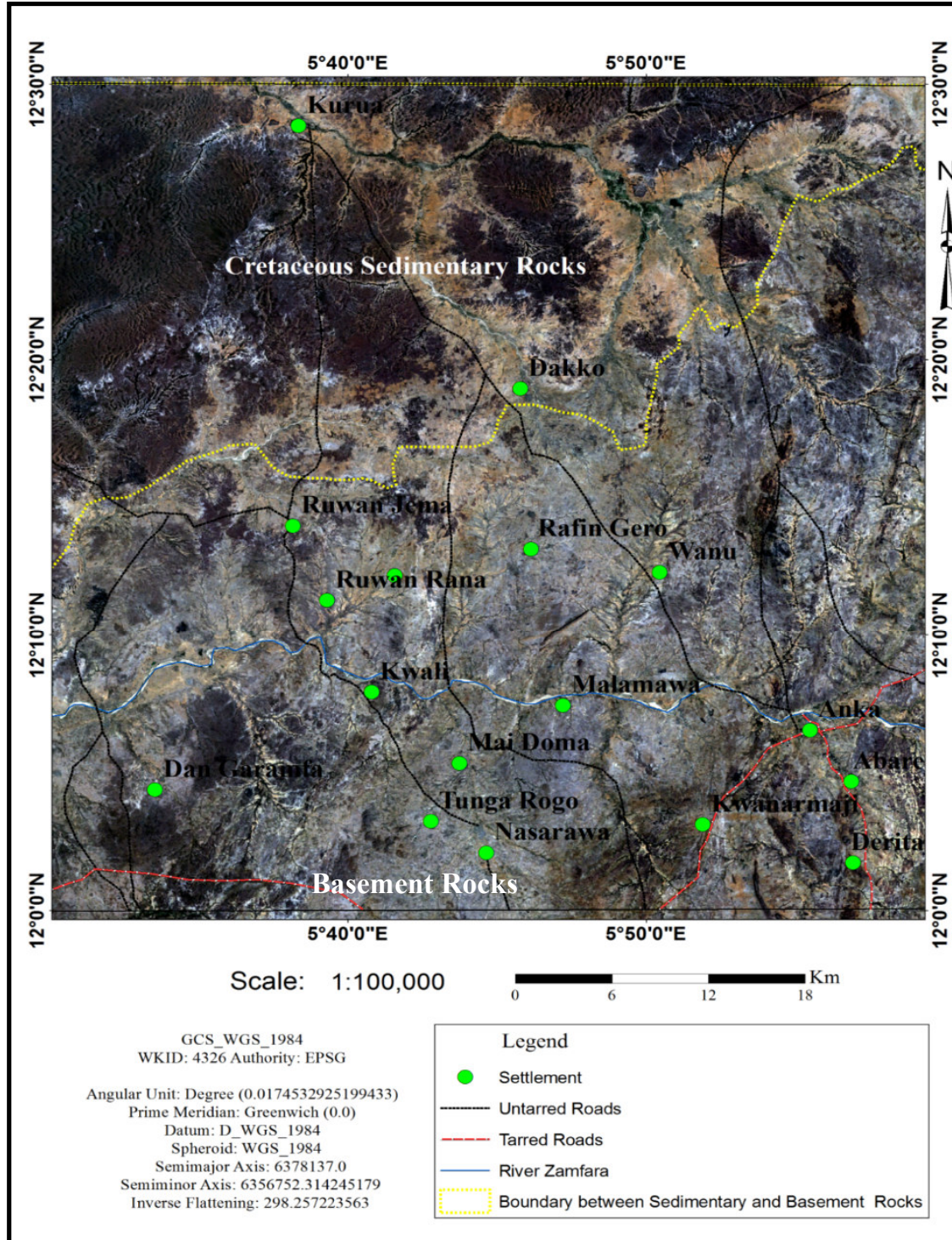

Figure 2: LandSat Imagery (Band 321) of the study area showing boundary between basement and sedimentary rock units. 


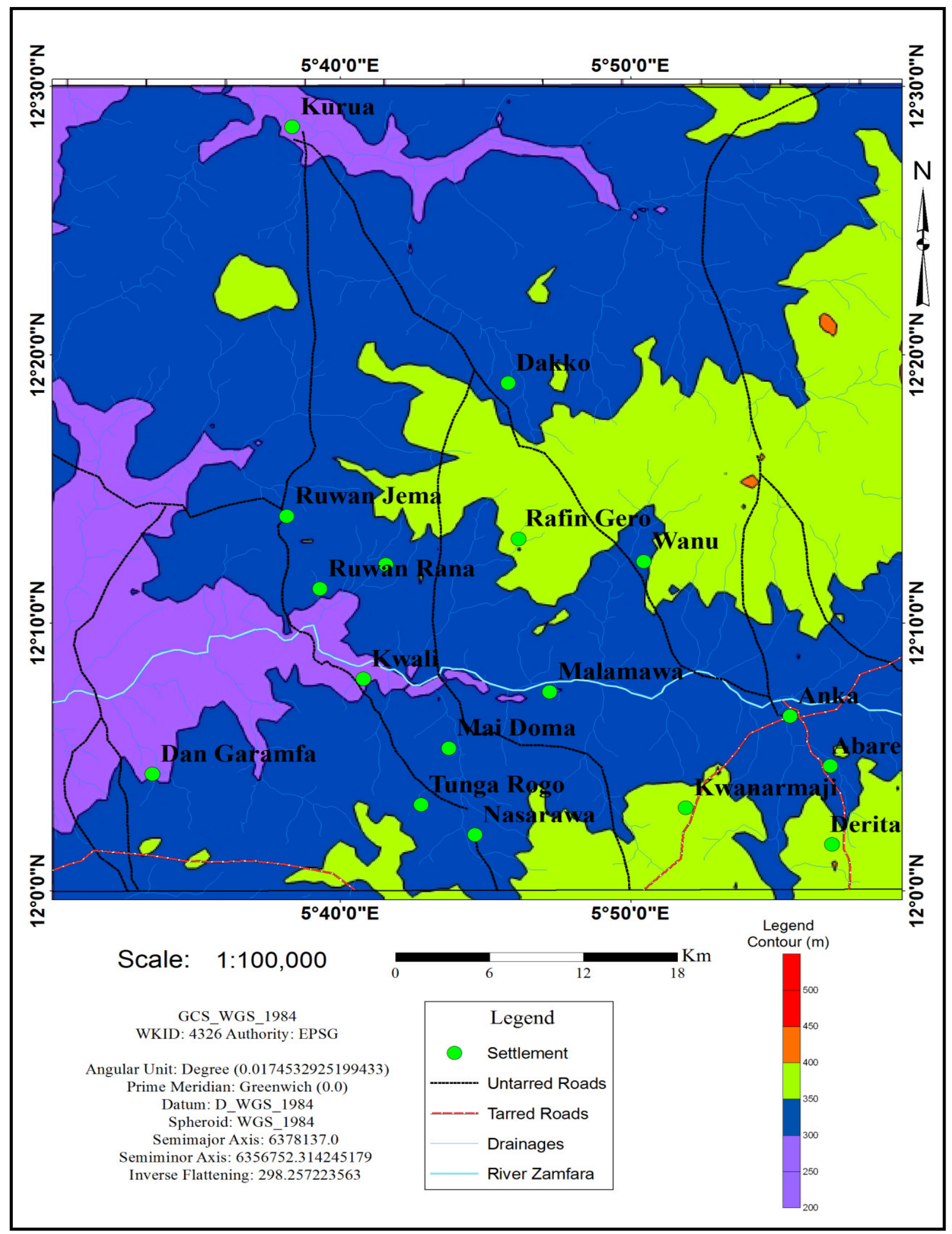

Figure 3: Digital elevation model (DEM) of the study area 


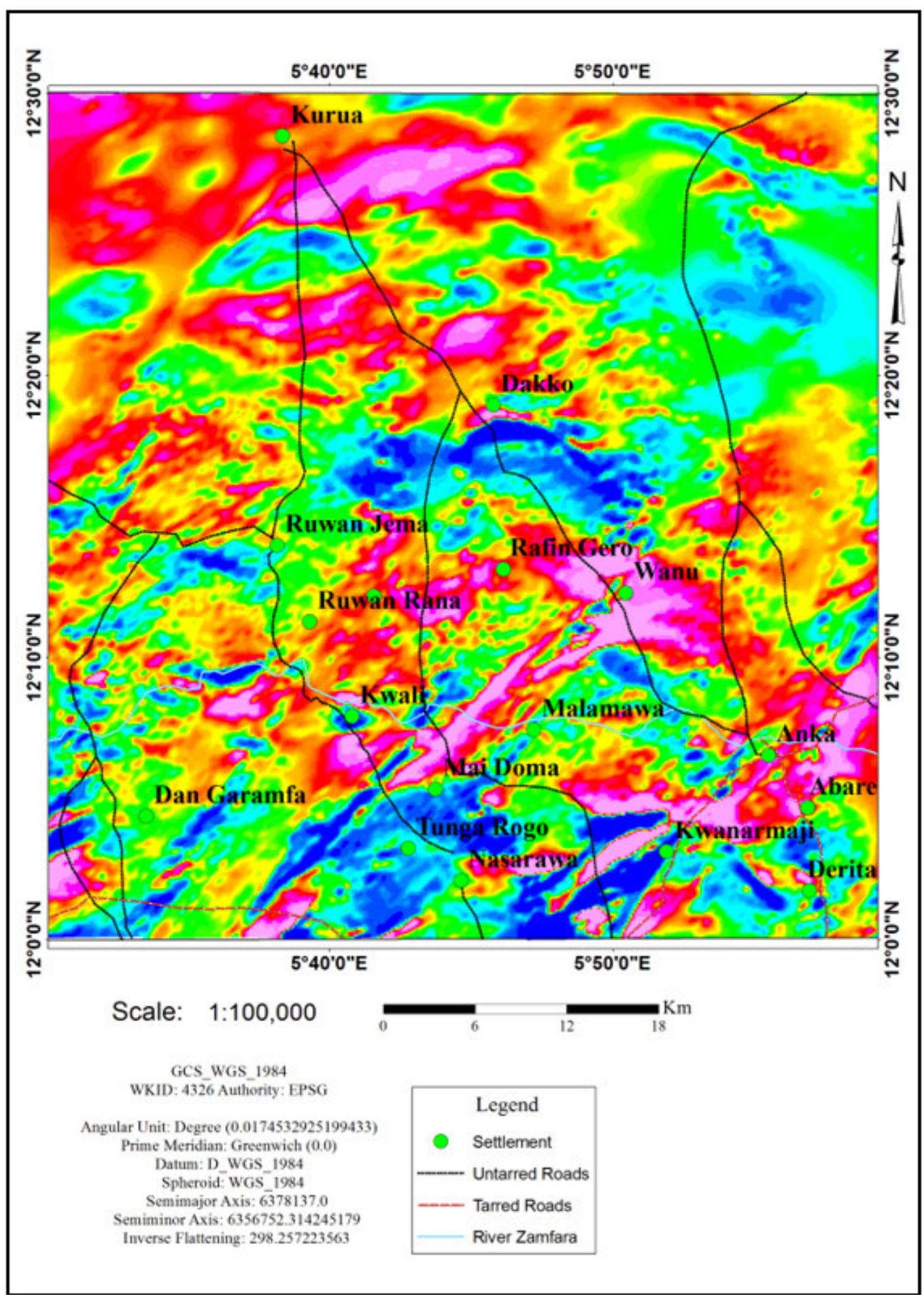

Figure 4: Total Magnetic Intensity (TMI) map of the study area 


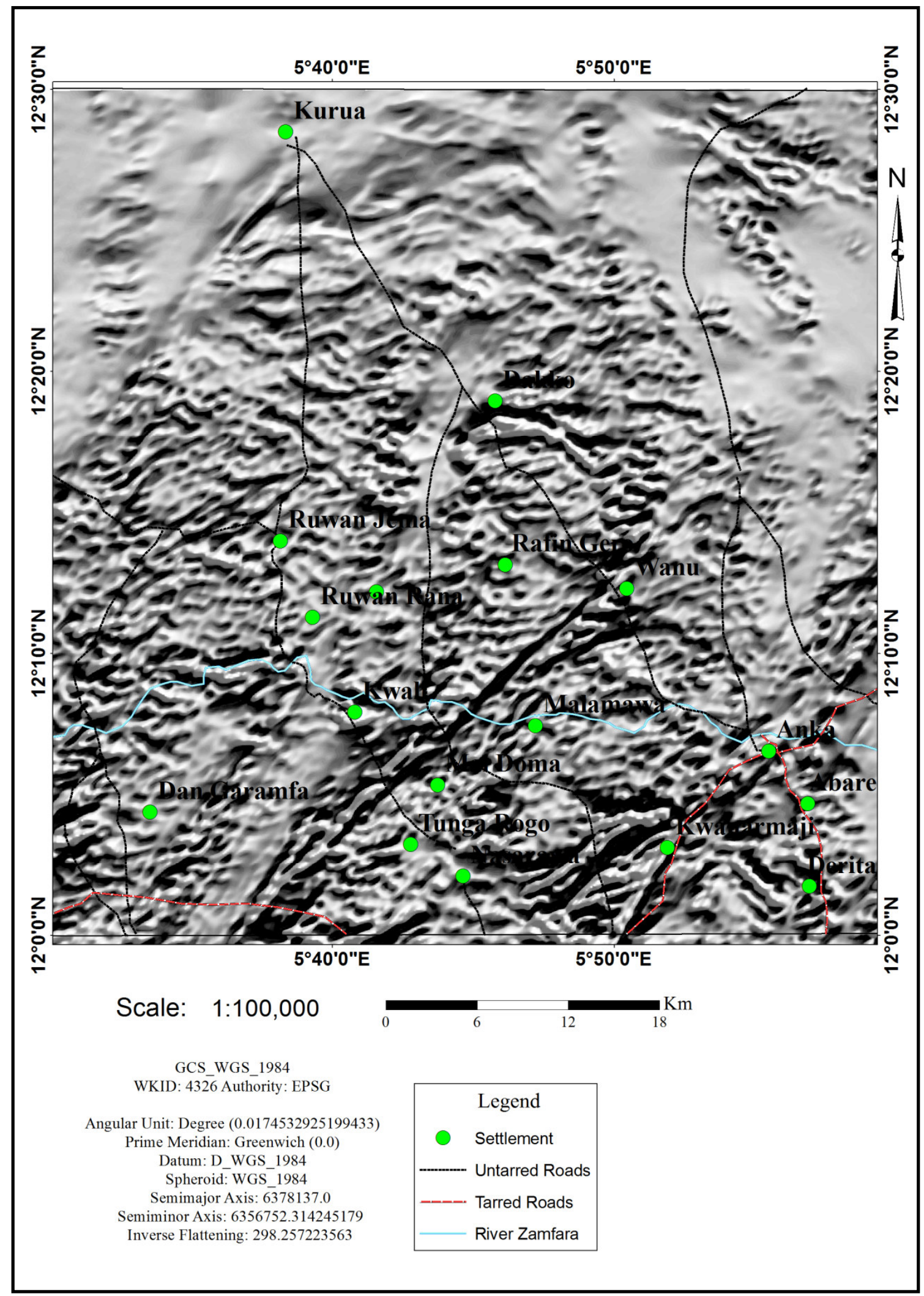

Figure 5: First Vertical Derivative (1VD) map of the study area 


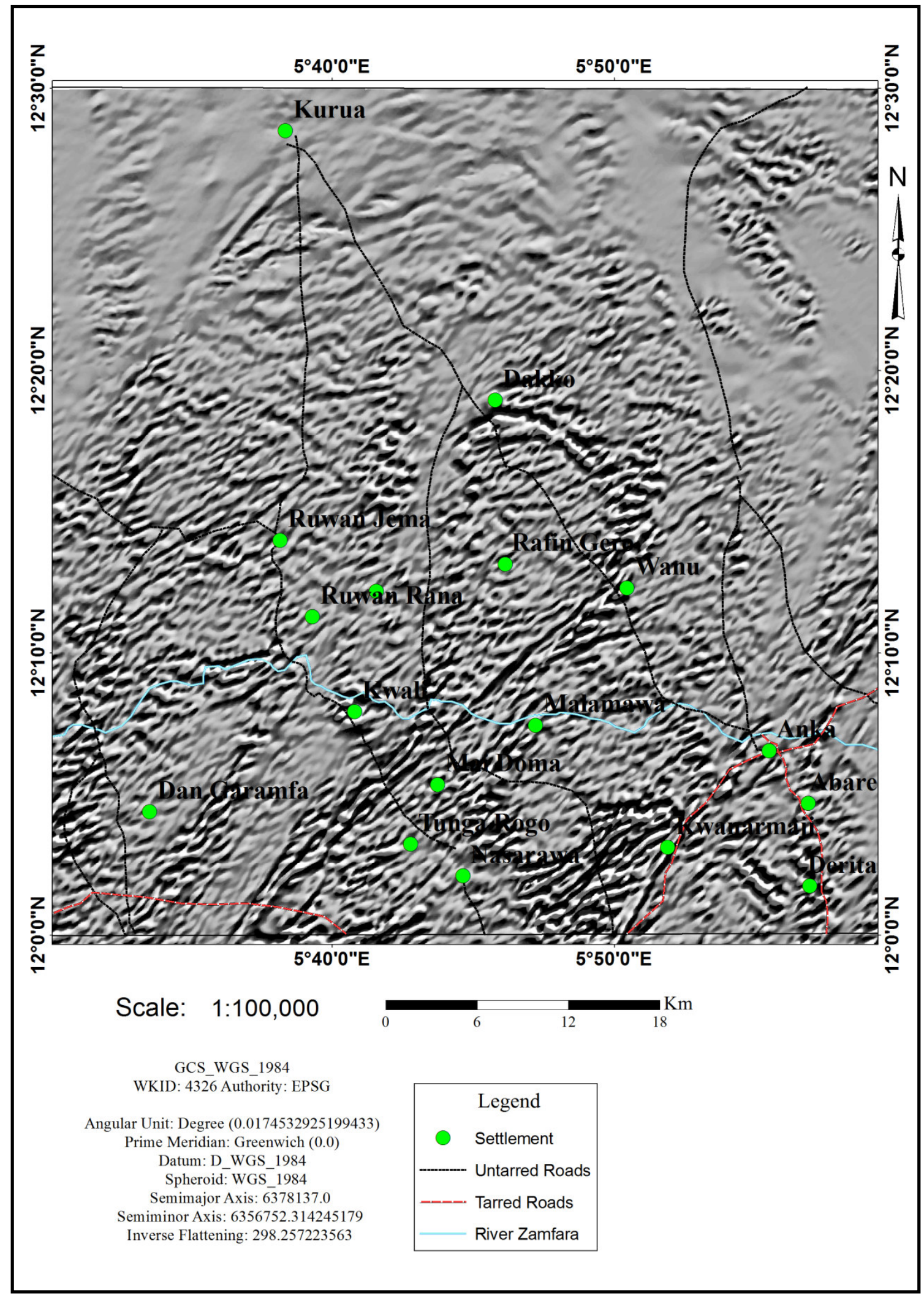

Figure 6: Second Vertical Derivative (2VD) map of the study area 


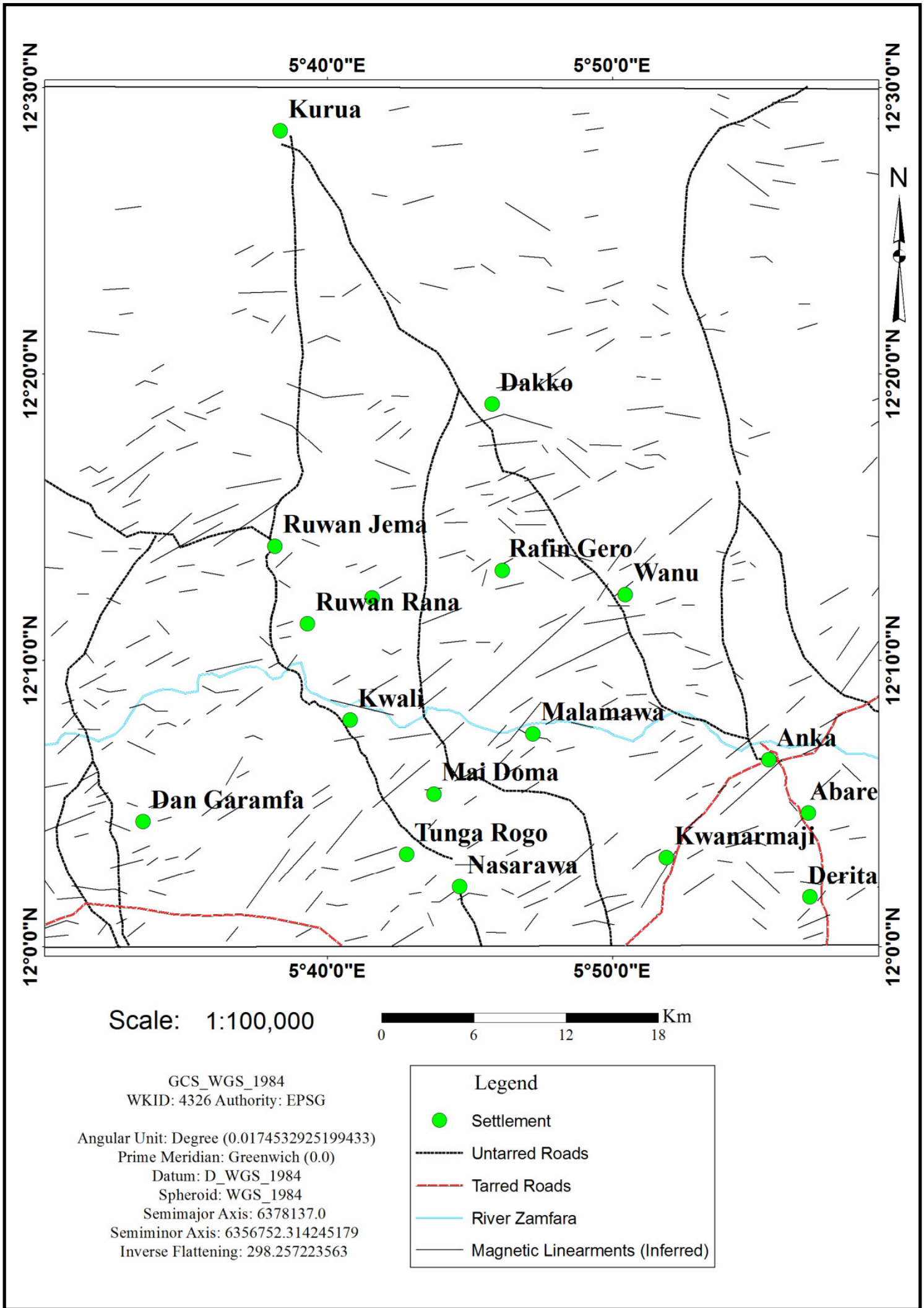

Figure 7: Structural lineaments map of the study area base on magnetic data analysis 


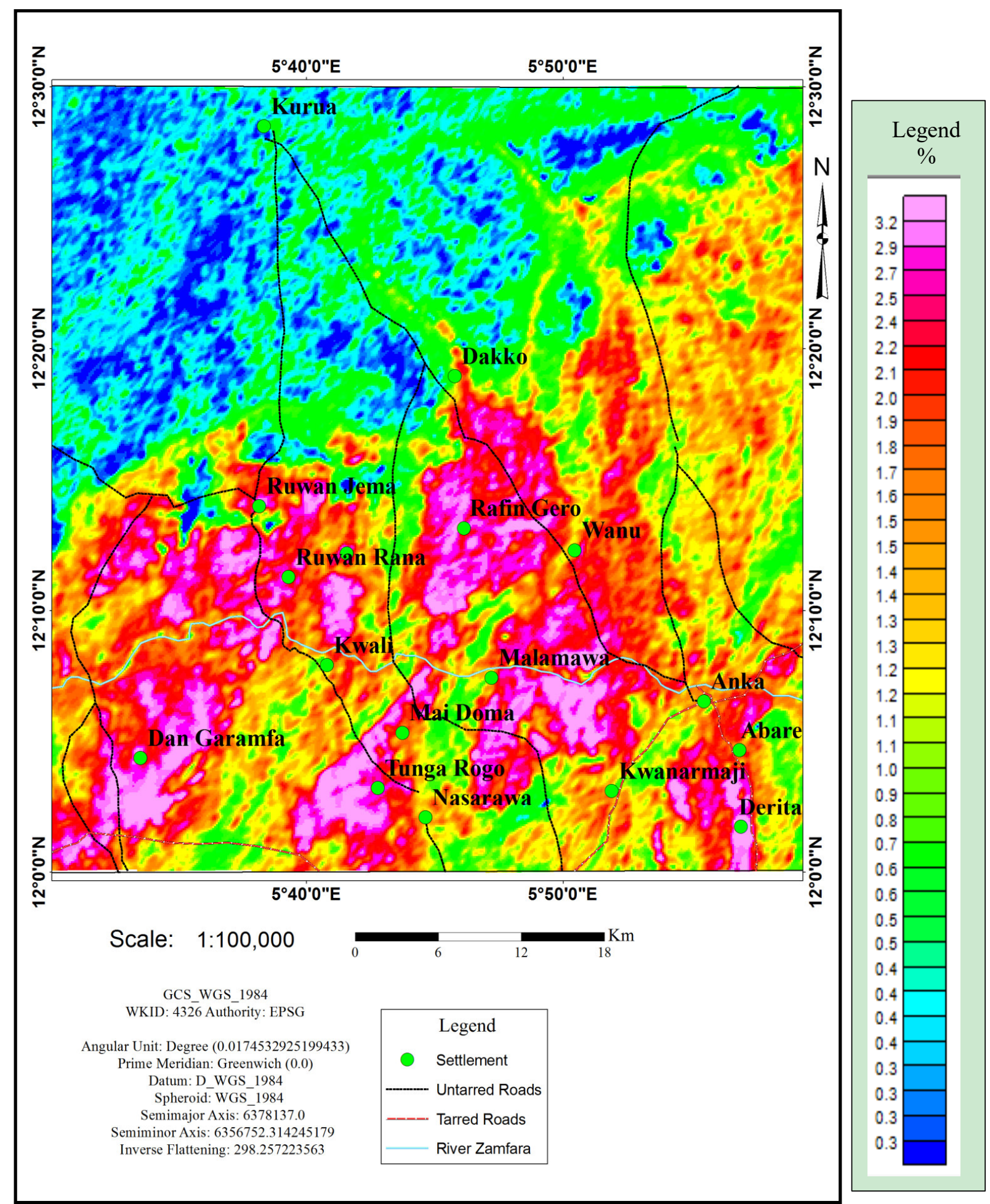

Figure 8: Potassium (K) composite image map 

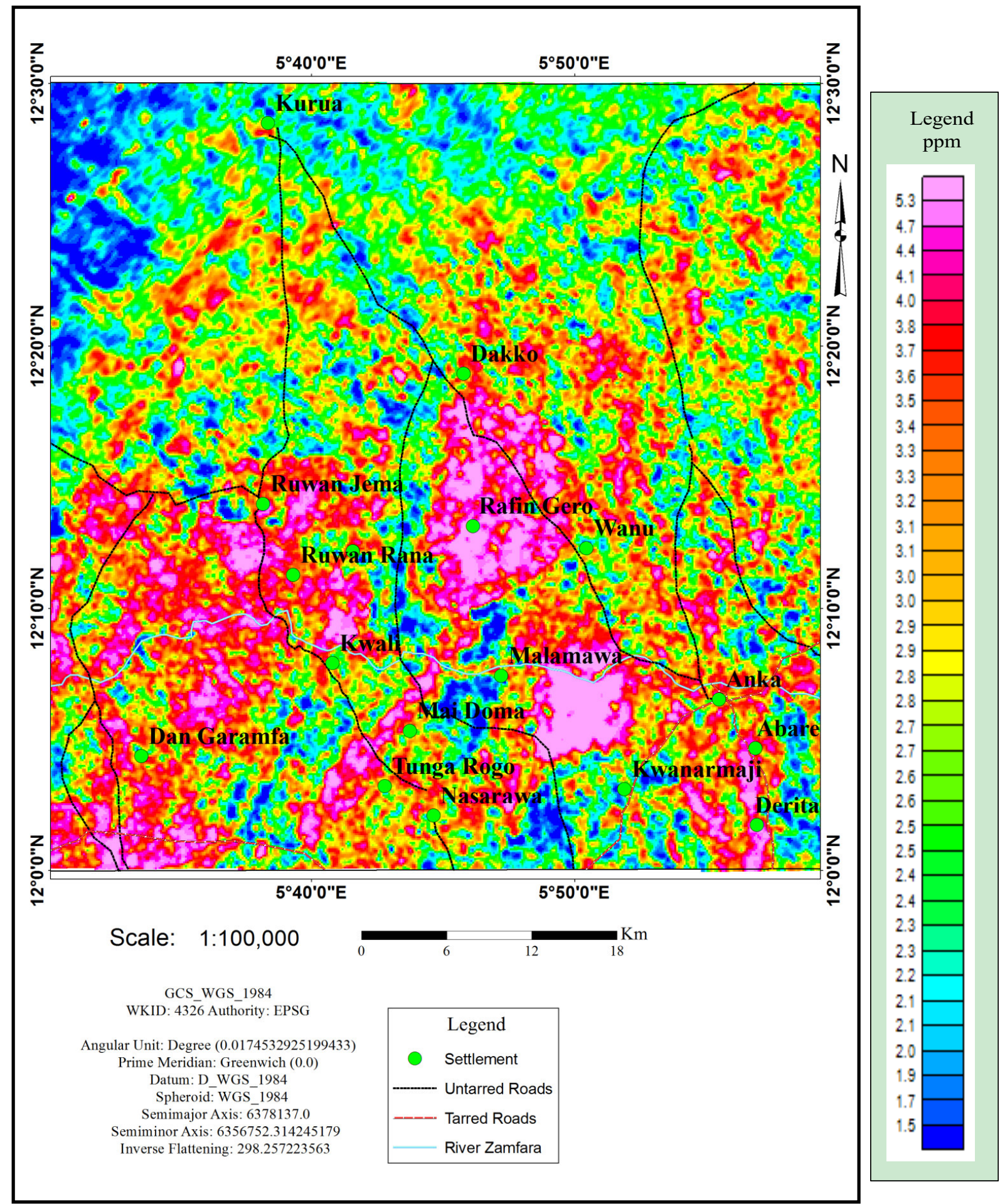

Figure 9: Uranium (U) composite image map 

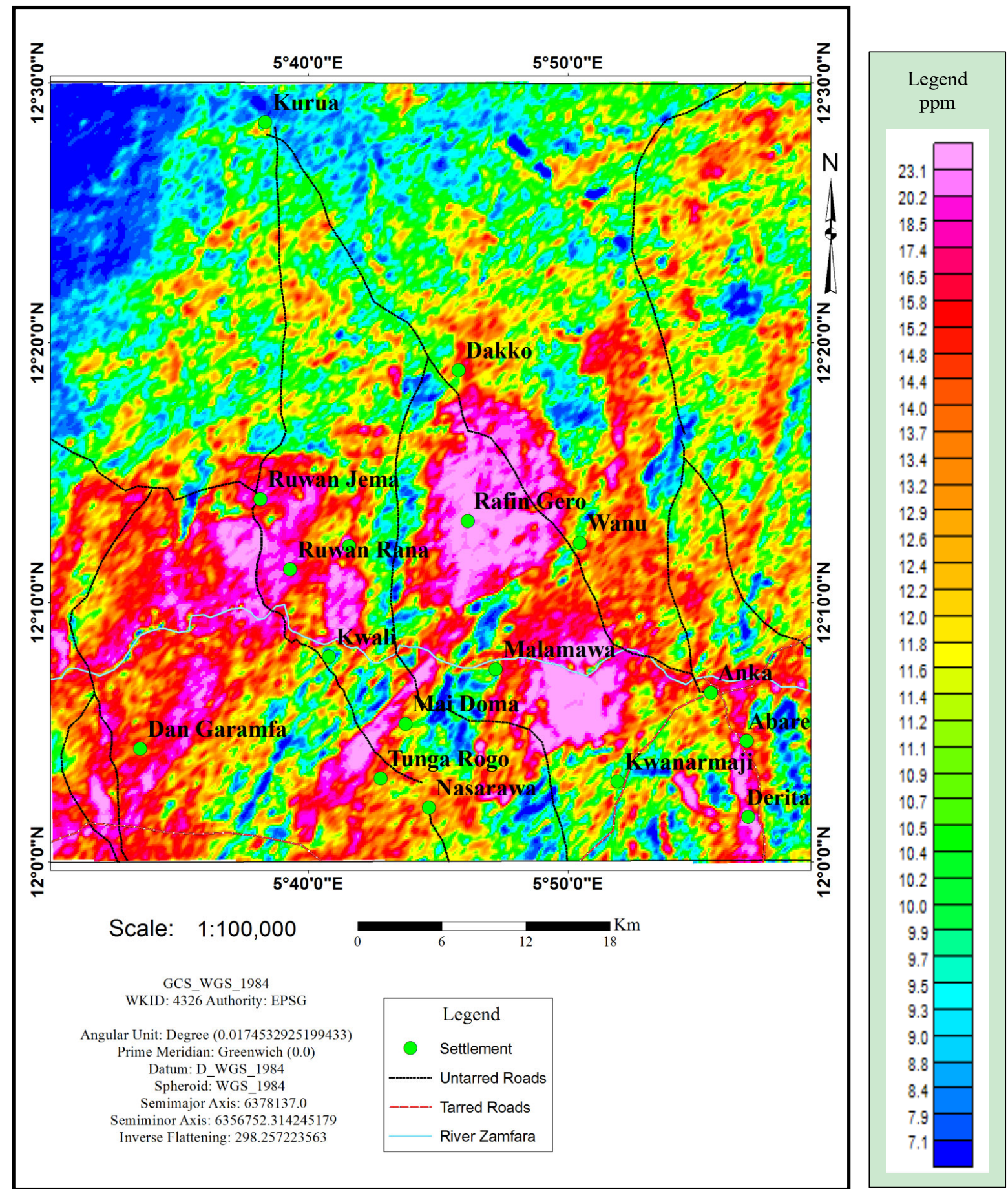

Figure 10: Thorium (Th) composite image map 


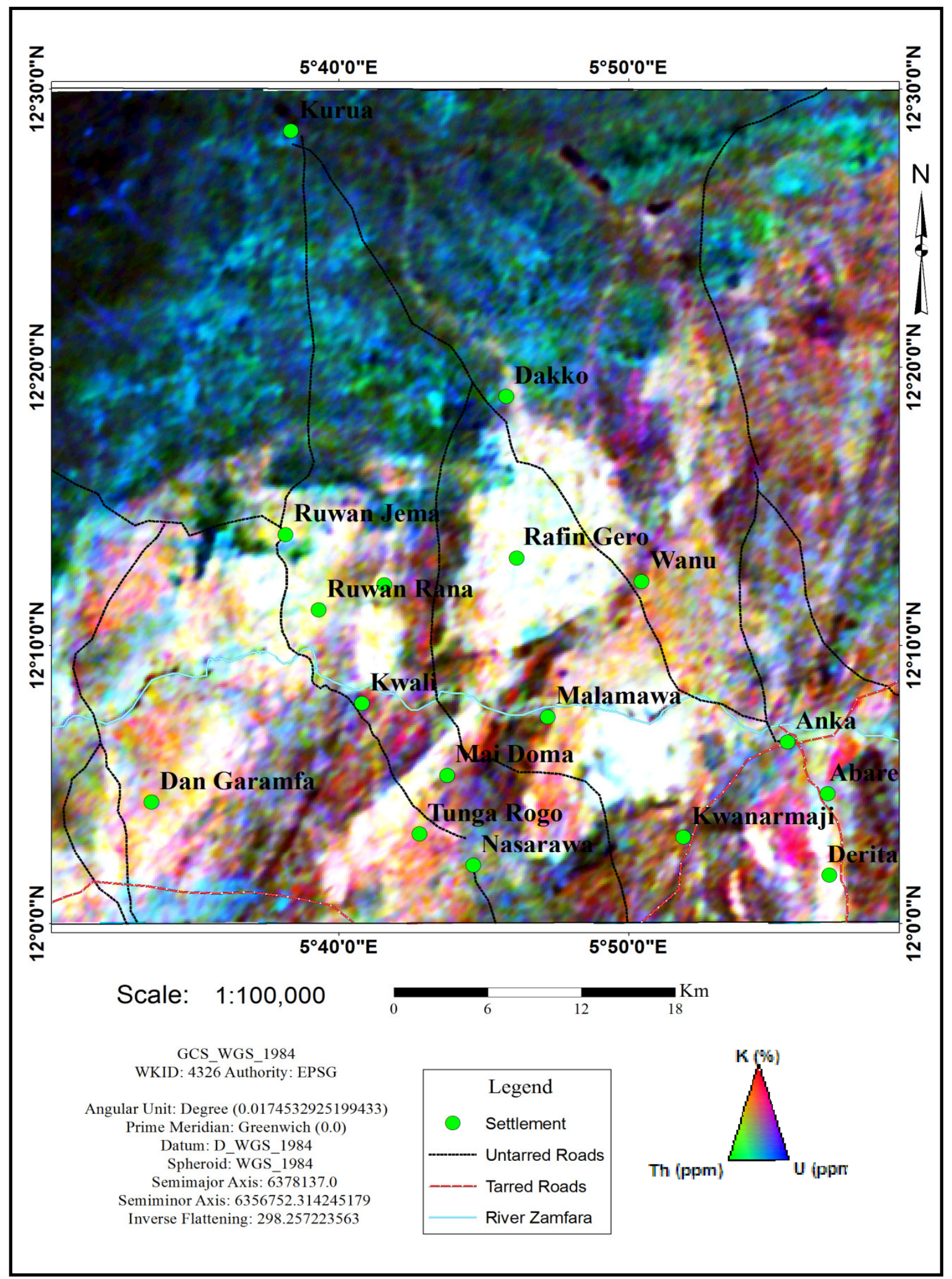

Figure 11: Radioelements composite image map 


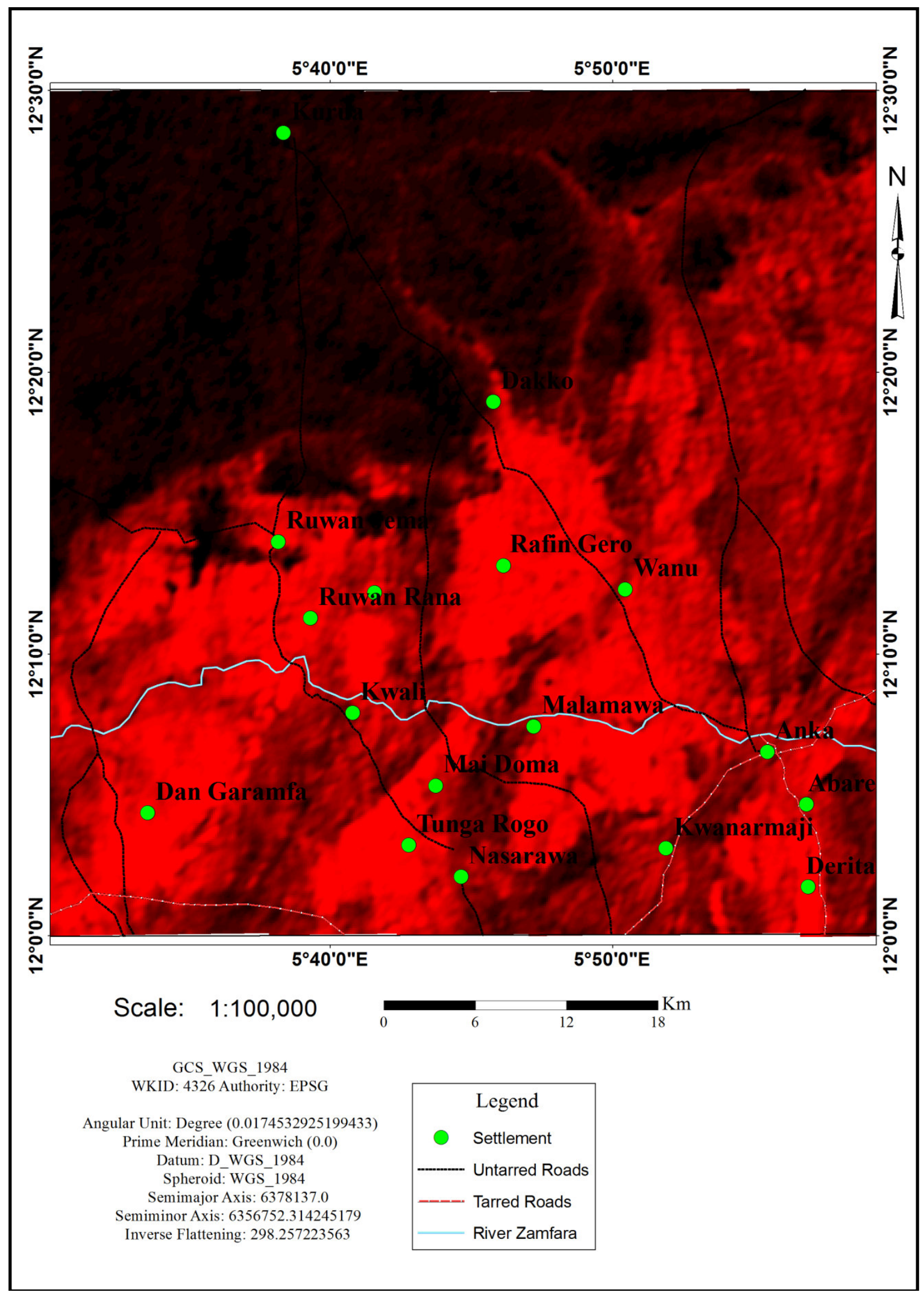

Figure 12: Enhanced radioelements composite image map 


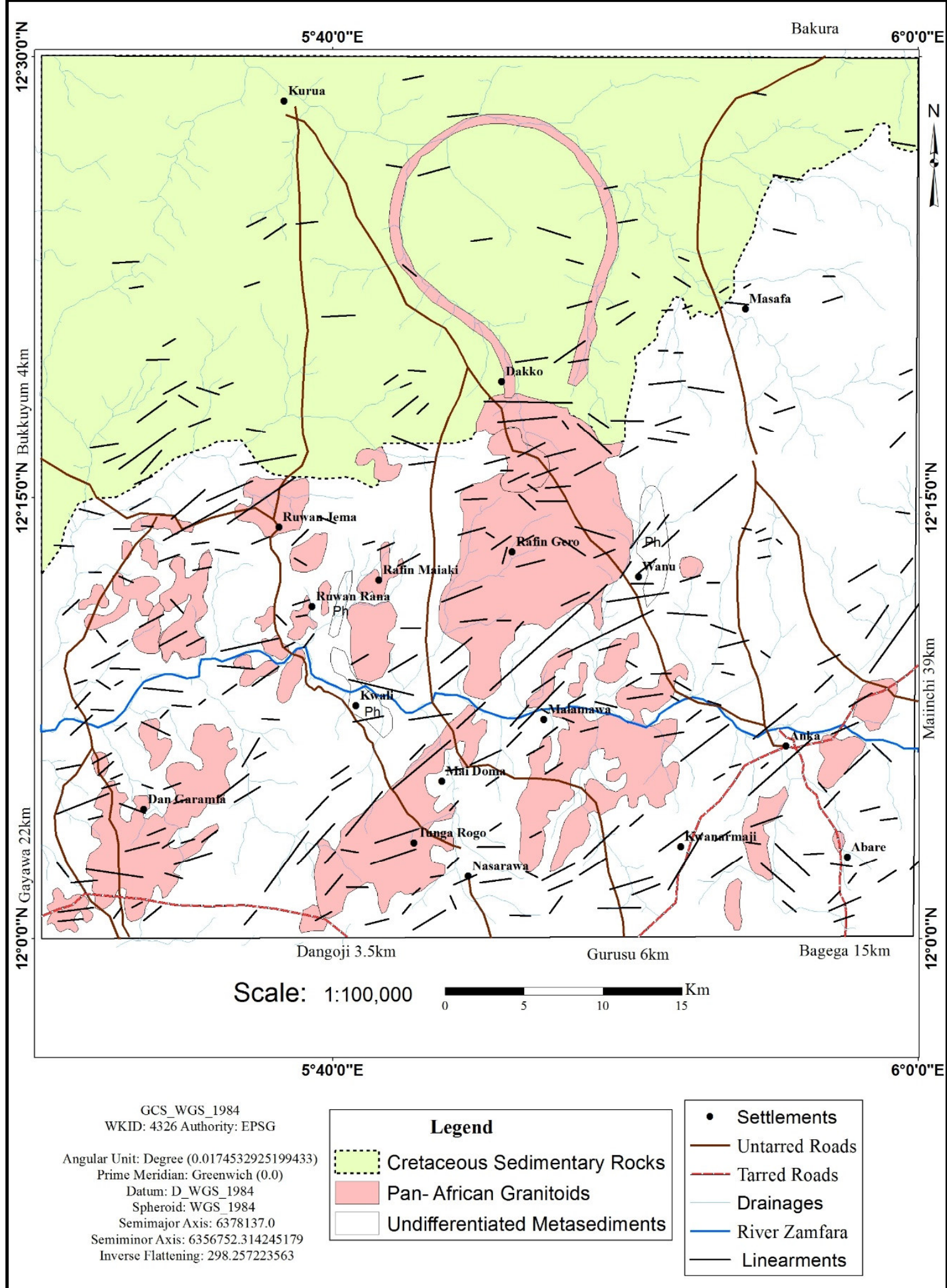

Figure 13: Interpreted geological boundary and structural lineament map of the study area

\section{Discussion}

Recently, major advances have been achieved in remote sensing applications from global to local scale. Over 50\% of the study area covers an elevation ranging from 300m-350m from north to south, however the eastern and some part of the south-eastern corner of the area covers elevation between $350 \mathrm{~m}-400 \mathrm{~m}$. Elevation in the mid-western part is as low as $200 \mathrm{~m}$ above sea level. River Zamfara, a major river runs from east to west for more than $50 \mathrm{~km}$ in 
the southern part of study area. Drainages within the study area is generally controlled by such elevations from highest to lowest points by discharging its contents into river Zamfara which is positioned in the southern part of the area at elevation much lower than $300 \mathrm{~m}$ above sea level. Landsat imagery with band combinations of 321 clearly reveals that the study area falls largely within a crystalline basement rocks up to $60 \%$ while the remaining $40 \%$ is covered by sedimentary rocks to the north. The interpreted image reveals the presence, nature, orientation and spatial distribution of features within the area such as rivers, streams and vegetation which predominate within the sedimentary rocks in the north. Suzen and Toprak [7] stated that structural lineament data can be visually enhanced using image enhancement techniques (image ration, image fusion, directional edge-detection filters) and a lineament vector map can be produced using manual digitizing techniques. To extract and construct structural lineament map within the study area, a high resolution aeromagnetic satellite imagery covering the study area was processed and analyzed for structurally controlled lineaments. Results revealed a major NE-SW trending for almost $25 \mathrm{~km}$ referred to as the Anka Fault and other subsidiary lineaments trending NW-SE with few E-W trends. This is similar to those observed by [8]; [9]. High-sensitivity airborne radiometric spectrometry survey data was used to study the surface geology of the study area. The composite image technique was applied to the spectrometry data to facilitates the correlation and delineation of lithologic units based on direct measurement of the surface distribution of the naturally occurring radioelements $(\mathrm{K}, \mathrm{U}$, and $\mathrm{Th})$ is made possible by gamma-ray spectrometry (GRS). Potassium is a major constituent of most rocks, while Uranium and thorium are present in trace amounts, as mobile and immobile elements, respectively. Since the concentration of these radioelements varies between different rock types, the measured radioelement distribution was used to map and distinguish the different lithologies. The method proved worthy to subdivide the Basement complex rocks into Pan-African Granites from the Metasediments. The most eye-catching feature in the enhanced composite images is the basement-sedimentary contact. This contact is associated with dramatically change in the radioelement concentrations and can be easily distinguished in the radioelement and potassium composite images. The granitic body, located in the northcentralsouthern part of the study area is interpreted as intrusions into the metasediments on the basis of this study.

\section{Conclusion}

From literature review, the study area (Anka sheet 52) falls within the Anka schist belt comprising of Precambrian to Pan-African basement and cretaceous sedimentary rocks. The combination results obtained from the interpretations of Landsat $\mathrm{ETM}^{+}$, Shuttle Radar Thematic Mapper (SRTM) data for Digital Elevation Model (DEM), Airborne Magnetic and Radiometric has demonstrated a method to map structural lineaments distribution and clear demarcation of geological boundaries. The processed images from these techniques show that the application is helpful for reconnaissance prior to ground geological mapping as regional area would have been covered meaningfully to support field exercise.

\section{References}

[1] Maged, M., Mansor, S. and Hashim, M. (2009). Geologic mapping of United Arab Emirates using multispectral remotely sensed data. Amer. Journal of Engineering and Applied Science, (2), p.476-480.

[2] Mostafa, M. E. and Bishta, A. Z. (2005). Significant of lineament pattern in rock unit classification and designation: A pilot study on the gharib-dara area. Northen eastern Desert, Egypt. International Journal of Remote Sensing, (7), p.1463 - 1475.

[3] Semere S, Ghebreab, W. (2006). Lineament characterization and their tectonic significance using Landsat TM data and field studies in the central highlands of Eritrea. Journal of African Earth Sciences, (4), p.371-378.

[4] Garba, A. (2018). Mineral resources of Nigeria and a synopsis of proof of concept committee meeting A paper presentation at the (MinDiver) meeting, Abuja, p.6.

[5] Farr, T. G. (2007). The Shuttle Radar Topography Mission. Reviews of Geophysics (45) p.1-33.

[6] Urquhart, W. E. S. (1988). Decorrugation of Enhanced Magnetic Field Maps. Paper presented at the 55th Annual Meeting of SEG, Anaheim.

[7] Süzen, M. L. and Toprak, V. (1998). Filtering of satellite images in geological lineament analyses: An application to a fault zone in central Turkey. International Journal on Remote Sensing, (6), p.101-1114.

[8] Holt, R. (1982). Geotectonic evolution of the Anka schist belt in the Precambrian basement complex of northwestern Nigeria. Unpublished Ph.D. Thesis, Open University, England, p.254.

[9] Danbatta, U. A. (2008). Precambrian crustal development in the northwestern part of Zuru schist belt, northwestern Nigeria. Journal of Mining and Geology, (44), p.45-56. 